\title{
Gestão do SUS: Interfederativa e participativa
}

Sergio SCHIERHOLT ${ }^{1}$

Helena Eri SHIMIZU ${ }^{2}$

\section{O FEDERALISMO BRASILEIRO E A POLÍTICA DE SAÚDE}

O Brasil se organiza em um sistema político federativo constituído por três esferas de governo - União, Estados e Municípios, todas consideradas pela Constituição de 1998 como entes com autonomia administrativa sem vinculação hierárquica. São 27 Estados e o Distrito Federal somados com 5.570 municípios. Os Estados, regiões e municípios são marcados por enormes diferenças, tanto socioculturais, como quanto ao seu contingente populacional. O sistema federativo adotado pelo país contribui para promover essa diversidade e heterogeneidade, por favorecer o respeito aos valores democráticos em situação de demarcada diferenciação política, cultural, religiosa ou social. 1

Entretanto, esse tipo de sistema torna mais complexa a implementação de políticas sociais de abrangência nacional, particularmente nos casos em que a situação de diversidade diz respeito à existência de enormes desigualdades e exclusão social. Além disso, a implementação de polícias sociais em um sistema federativo requer a explicitação das funções das diferentes esferas de governo para cada área da política, além da adoção de mecanismos articuladores entre essas esferas, com ênfase em uma lógica de cooperação e complementação.2

No quesito políticas de saúde, agregue-se a isso a complexidade inerente à área relacionada aos seguintes fatores: múltiplas determinações sobre o estado de saúde da população e dos indivíduos; diversidade das necessidades de saúde em uma população heterogênea; diferentes tipos de ações e serviços necessários para dar conta dessas necessidades; capacitação de pessoal e recursos tecnológicos requeridos para atendê-las; interesses e pressões do mercado na área da saúde (no âmbito da comercialização de equipamentos, medicamentos, produção de serviços, entre outros) que frequentemente tencionam a estruturação de um sistema calcado na concepção de saúde como um direito de cidadania. 2 Para responder a estes desafios relacionados ao pacto federativo e a autonomia política dos seus três entes (federal, estadual e municipal), o modelo institucional proposto pelo SUS é extremamente ousado, na tentativa de concretizar o acordo entre os diferentes níveis de gestores do sistema, além de buscar o fortalecimento da participação social na formulação

1 Mestre em Ciências da Saúde pela Universidade de Brasília. Atualmente é pesquisador do Núcleo de Estudos em Saúde Pública da Universidade de Brasília e professor da Universidade de Brasília no campus da Ceilândia

2 Doutora em Enfermagem pela Universidade de São Paulo. É professora associado da Universidade de Brasília. Contato:shimizu@unb.br 
das políticas de saúde.

A lei n. 8080, de 1990, define a atribuição e responsabilidade de cada esfera governamental no desenvolvimento de suas funções e competências do Poder Executivo na saúde. A direção do SUS é única nos níveis nacional, estadual e municipal, sendo exercida, respectivamente, pelo Ministério da Saúde e pelas secretarias de Saúde dos seus níveis correspondentes.

O modelo de gestão do SUS pressupõe uma articulação estreita, conjunta e complexa dos seus principais espaços de representatividade em cada nível de governo: 1) gestores do sistema nos três níveis de governo; 2) instâncias de negociação e decisão envolvendo a participação das diferentes Gestão do SUS: Interfederativa e participativa esferas de governo (Comissão Intergestores Tripartite (CIT), no âmbito nacional, as comissões intergestoras bipartites (CIB), no âmbito estadual, e as Comissões Intergestores Regionais (CIR), no âmbito das Regiões de Saúde, nas quais se discute e decide-se de maneira consensual toda a gestão da saúde, de modo compartilhado e que substituem os atuais Colegiados de Gestão Regional (CGR). Além disso, 3) conselhos de secretários de Saúde nos âmbitos nacional e estadual; 4) conselhos de Saúde nos âmbitos nacional, estadual e municipal, além de realização periódica das conferências de Saúde. 3

Resumidamente, poderíamos dizer que os gestores do SUS atuam em dois âmbitos relacionados, o técnico e o político. Este último se expressa no relacionamento constante dos gestores do SUS com outros atores sociais, nos diferentes espaços de negociação e decisão existentes. O próprio desempenho das funções do Poder Executivo, em um sistema político republicano e democrático como o Brasil, e os objetivos a serem perseguidos na área da saúde exigem a interação do gestor com os demais órgãos de representação e atuação do governo e da sociedade civil organizada. Como no SUS existem instâncias de negociação e decisão, envolvendo a participação dos diferentes níveis gestores do sistema e de diversos segmentos representativos dos interesses da sociedade, destaca-se a participação dos gestores nos conselhos de saúde, nos conselhos de representação dos secretários de saúde (Conselho Nacional de Secretários de Saúde - Conass; Conselho Nacional dos Secretários Municipais de Saúde - Conasems; Conselho dos Secretários Municipais de Saúde dos Estados - Cosems), na CIT e nas CIB. 4

\section{PARTICIPAÇÃO SOCIAL E OS 25 ANOS DO SUS}

Durante esses vinte e cinco anos de consolidação, o SUS esteve, desde o início, alicerçado em três pontos: a universalização da assistência, o controle social e a normatização técnica das alocações financeiras.

Desses, apenas os dois primeiros pontos podem ser considerados como avanços percebidos com maior consistência. A questão do financiamento do sistema esbarra nas oscilações dos gastos nas três esferas governamentais, em questionamentos jurídicos quanto ao fluxo das transferências e na definição mais clara do perfil de necessidades sociais em termos de cobertura e modelo de assistência. A universalização da assistência é perceptível por meio do acesso proporcionado a 
clientelas não previdenciárias junto a hospitais e ambulatórios do ex-Inamps, ou conveniados, e da recente ampliação das redes municipais de saúde. 5

A questão do controle social, comumente referida à formação e atuação dos Conselhos de Saúde, tem se mostrado, por outro lado, a principal inovação política do SUS, e seu conceito básico de pactuação política entre grupos de interesses têm penetrado, inclusive, as próprias relações intergovernamentais, especialmente a partir da criação das comissões intergestores bipartite (CIB) e tripartite (CIT).

É preciso sublinhar que disposições do MS e do CNS impulsionaram a criação de tais instâncias, na medida em que condicionaram a transferência de recursos financeiros a estados e municípios com a existência de Conselho de Saúde no ente correspondente. Depois foram adicionados requisitos que tornaram imperativa a aprovação do plano de saúde, do orçamento e outros instrumentos de gestão. 6

Tais incentivos normativos, junto com a politização da questão saúde mediante a realização periódica de conferências de saúde em todo o país, têm permitido colocar a implementação do SUS em permanente questionamento e vigilância, formando-se uma massa crítica de apoio que tem assegurado, em boa parte, o aperfeiçoamento do sistema e a crescente participação cidadã, assentando as bases, embora ainda muito frágeis, para o almejado controle social dos usuários sobre as decisões e os atos das autoridades setoriais.

Como resultado concreto, atualmente há no país milhares de pessoas envolvidas nos Conselhos de Saúde. O porte de cada Conselho varia segundo o tamanho da população local, mas a regulamentação provê, para todos eles, a mesma composição paritária: metade dos assentos está reservada a representantes da autoridade setorial, dos profissionais, dos prestadores públicos e privados e dos trabalhadores da saúde; a outra metade deve ser ocupada por representantes dos usuários dos serviços do SUS. 7

Nesse caso, como ainda não existe no Brasil uma organização própria dos usuários, as entidades representadas nos Conselho de Saúdes são de natureza diversa, destacando-se as associações de portadores de patologias e deficiências e as associações de moradores de bairros e de favelas.

Em muitos Conselhos de Saúde se fazem representar os sindicatos de trabalhadores urbanos ou rurais, agregações, como as das mulheres, e os "clubes de serviço", como o Rotary Clube. Por outro lado, apesar de sua importância central, a medicina empresarial privada, da qual o SUS compra serviços, tem discreta presença nos Conselhos de Saúde. 8

O tema da representação nos CMS ainda gera muitas controvérsias e se busca mecanismos para alcançar uma paridade igualitária entre os segmentos, bem como a idoneidade dos representantes. Como a denominação "usuário" é vaga, as não raras "falsificações" na representação têm efeitos negativos, tanto em termos da democracia interna quanto em relação à legitimidade do Conselho 
de Saúde.

\section{FRAGILIDADES E DESAFIOS DA PARTICIPAÇÃO SOCIAL}

Aliteratura sobre os Conselhos de Saúde aponta que existem muitos problemas de funcionamento, atribuídos, em boa medida, à falta de tradição de participação e de cultura cívica no país. Dificuldades derivam também de questões regulamentares que afetam o resultado das resoluções adotadas. Por exemplo, de acordo com as normas constitucionais, cabe ao Secretário de Saúde, como representantesetorial do Poder Executivo nos estados e municípios, a iniciativa de formular e decidir em seu campo de ação. Assim mesmo, de acordo com a prática vigente, também coube a essa autoridade presidir o Conselho de Saúde. 9

A isso se soma a complexidade dos assuntos discutidos, em particular os financeiros, sobre os quais as pessoas "leigas" não têm conhecimento.

Isso tem levado a diversas iniciativas de capacitação de conselheiros que, junto com uma espécie de "profissionalização" dos representantes dos usuários, possibilitada pela sucessiva eleição ou indicação dos mesmos indivíduos, têm permitido que adquiram alguma familiaridade com as matérias relativas a políticas, programas, ações e serviços de saúde.

Tendo em vista essa necessidade dos conselheiros e cidadãos em geral, pode-se dizer que uma política de educação em saúde é também um alicerce da sociedade democrática assentada na cidadania na medida em que pode contribuir de maneira essencial para que os cidadãos se apropriem dos complexos e contraditórios elementos da realidade e se capacitem para sua efetiva transformação.

Constitui-se, por isso, em um dos elementos estruturantes para a efetivação do controle social no SUS. Uma política pública de educação em saúde, que assuma a prioridade e o caráter estratégico da questão, deve buscar reverter o quadro atual em que grande parte dos conselheiros municipais de saúde não sabe o que fazer, mesmo com as poucas informações já disponíveis. 10

O exercício do controle social sobre a gestão do sistema de saúde foi o objetivo primordial que se teve em mente ao idealizar os Conselhos de Saúde e as Conferências de Saúde. Porém, essa meta é a mais difícil de alcançar porque implica profundas mudanças na cultura política e cívica do país. De fato, apesar da plena vigência das instituições democráticas, ainda apresentam forte clientelismo político expresso na concessão de benefícios como se fossem favores pessoais, criando-se relações de dependência pessoal.

Por isso mesmo, os Conselhos e as Conferências de Saúde adquirem importância crucial, já que constituem um espaço único para o desenvolvimento de atitudes comprometidas com a cidadania e com o interesse geral. 


\section{REFERÊNCIAS BIBLIOGRÁFICAS}

1. SANTOS, M. Atlas Nacional do Brasil. IBGE, Rio de Janeiro, 2010. Pag. 28-31.

2. BRASIL. Conselho Nacional de Secretários de Saúde. Para entender a Gestão do SUS. Brasília, 2003. Pag. 14-20.

3. BRASIL. Lei nº 8.080, de 19 de dezembro de 1991. Dispõe sobre as condições para a promoção, proteção e recuperação da saúde, a organização e o funcionamento dos serviços correspondentes e dá outras providências. Diário Oficinal da União. Dezembro de 1990.

4. NORONHA, J.C.; LIMA, L.D.; MACHADO, C.V. O Sistema Único de Saúde - SUS. In: Políticas e Sistema de Saúde no Brasil. Rio de Janeiro - Editora Fiocruz/CEBES, 2008. Pag. 435450.

5. RIBEIRO, J. M. Conselhos de saúde, comissões intergestores e grupos de interesses no Sistema Único de Saúde (SUS).Cad. saúde pública, Rio de Janeiro, v. 13, n. 1, p. 81-92, jan./mar. 1997.

6. BRASIL. Lei n ${ }^{\circ} 8.142$, de 19 de dezembro de 1991. Dispõe sobre a participação da comunidade na gestão do Sistema Único de Saúde - SUS e sobre as transferências intergovernamentais de recursos financeiros na área da saúde. Diário Oficial da União, Dezembro de 1990.

7. BRASIL. Ministério da Saúde. Conselho Nacional de Saúde. Resolução no 333, de 4 de novembro de 2003. [Aprova as diretrizes para criação, reformulação, estruturação e funcionamento dos Conselhos de Saúde]. Diário Oficial da União, Poder Executivo, Brasília, DF, n. 236, 4 dez. 2003. Seção 1, p. 57.

8. Conselho Nacional de Secretários de Saúde (Brasil). A saúde na opinião dos brasileiros: um estudo prospectivo. Brasília : CONASS, 2003.

9. LABRA, M. E.; GIOVANELLA, L. Estudio de caso: Brasil, construcción del Sistema Único de Salud y participación de la sociedad civil. Rio de Janeiro : Fiocruz/Red de Investigación en Sistemas y Servicios de Salud del Cono Sur, 2007.

10. ASSIS, Marluce Maria Araújo; VILLA, Tereza Cristina Scatena. Social control and information democratization: a process under construction.Rev. latinoam. enferm., Ribeirão Preto, v. 11, n. 3, p. 376- 82, May/Jun. 2003.

Artigo apresentado em 11/01/14

Artigo aprovado em 22/03/14 Artigo publicado no sistema: 29/03/14 